\title{
Handling and stocking-density effects on growth rhythms of brook trout, Salvelinus fontinalis
}

\author{
Wafa Aboul Hosn, Pierre Dutilleul, and Daniel Boisclair
}

\begin{abstract}
We evaluated the effects of handling and stocking density ( 3 vs. 6 fish/150 L) on the growth-rate rhythms of brook trout, Salvelinus fontinalis. The length of nonhandled fish was estimated with a stereo-video technique and the length and mass of handled fish was measured directly. The main effects of handling and stocking density and their interactions on growth rates were not statistically significant, whereas the main effects of time were significant, as shown by repeated measure analysis. Multifrequential periodogram analysis indicated significant infradian rhythm components of about $8 \mathrm{~d}$ in the relative growth rate in length and of about 5 and $11 \mathrm{~d}$ in the relative growth rate in mass, regardless of the treatment applied. The characteristics (period, amplitude, and phase) of the rhythms found were not altered, either by handling or by stocking density.
\end{abstract}

Résumé : Nous avons évalué les effets des manipulations et de la densité dans les élevages (3 vs. 6 poissons/150 L) sur le taux de croissance de l'Omble de fontaine, Salvelinus fontinalis. La longueur des poissons non manipulés a été estimée au moyen d'une technique stéréo-vidéo alors que la longueur et la masse des poissons manipulés ont été mesurées directement. Les principaux effets de la manipulation et de la densité, de même que de leurs interactions sur les taux de croissance, n'étaient pas statistiquement significatifs, alors que les principaux effets du temps l'étaient, comme l'a démontré l'analyse des mesures répétées. Les résultats d'une analyse harmonique à plusieurs fréquences semblent indiquer l'existence d'un rythme infradien d'environ 8 jours pour le taux de croissance relative en longueur et d'environ 5 et 11 jours pour le taux de croissance relative de la masse, indépendamment du traitement administré. Les caractéristiques (période, amplitude, phase) des rythmes sont demeurés inchangés et n'ont été affectés ni par les manipulations, ni par la densité dans les élevages.

[Traduit par la Rédaction]

\section{Introduction}

Fish exhibit rhythmic patterns of growth at several temporal scales (Planes 1993). Circadian (Pannella 1971; Campana and Neilson 1982) and seasonal (Brown 1946; Fonds 1979; Wang and Houde 1994), as well as lunar or semilunar rhythms (Campana 1984; Wagner and McKeown 1985; Farbridge and Leatherland 1987), have been reported in the literature.

Using advanced statistical techniques that have not been used in previous studies on growth rhythms in fish, Aboul Hosn et al. (1997) demonstrated the existence and repeatability of rhythms of 5 and $10 \mathrm{~d}$ in the growth in mass and of 4 to $6 \mathrm{~d}$ in the growth in length of brook trout, Salvelinus fontinalis. The detection of such periodicities (i.e., $4 \mathrm{~d}$ ) required a short sampling time interval (i.e., 2 d). In addition, the test for repeatability of rhythms required the collection of replicated time series (i.e., growth-rate records of individual fish), which are necessary for the relevant analyses in the frequency domain. Therefore, marking and frequent handling,

Received July 16, 1999. Accepted February 28, 2000.

W. Aboul Hosn ${ }^{1}$ and P. Dutilleul. Department of Plant Science, Macdonald Campus of McGill University, 21,111 Lakeshore, Ste-Anne-de-Bellevue, QC H9X 3V9, Canada. D. Boisclair. Département de sciences biologiques, Université de Montréal, C.P. 6128 Succursale Centre-Ville, Montréal, QC H3C 3J7, Canada.

${ }^{1}$ Author to whom all correspondence should be sent at the following address: Statikron Consultants, 89 Beaconsfield Boulevard, Beaconsfield, QC H9W 3Z5, Canada (e-mail: wafa.hosn@attcanada.net). such as dip-netting, anaesthetizing, weighing, and length measurement, were necessary in the experimental procedures undertaken in these studies.

Handling and crowding have been shown to cause stress in fish, handling as an acute stressor (Eddy 1981) and crowding as a chronic stressor (Vijayan et al. 1990; Vijayan and Moon 1992). Stessors in general have been shown to elicit stress responses in fish, such as elevations in plasma-cortisol and plasma-glucose levels (Mazeaud and Mazeaud 1981; Leatherland and Sonstegard 1984). Elevated cortisol mobilizes energy, and hence enables the fish to respond to immediate threat (Schreck 1981). This increased energy demand, however, is thought to be met at the expense of anabolic processes, which might subsequently impair the performance and growth of fish (Pickering 1990; Vijayan et al. 1990; Barton and Iwama 1991). Behavioural changes induced by stressors may also reduce feeding rate (Brown et al. 1987).

The possible growth reduction caused by stressors might have implications for the estimation of fish growth rates and the detection of periodicities in time-series data developed to describe fish physiological rhythms (Aboul Hosn et al. 1997). Consequently, we conceived the present experiment, to assess the effects of handling and stocking density on the growth rates and growth rhythms of fish.

\section{Materials and methods}

\section{Experimental design}

Young-of-the-year brook trout $(21.05 \pm 0.75$ (SE) g wet mass; $13.11 \pm 0.17 \mathrm{~cm}$ total length) were kept in $700-\mathrm{L}$ aquaria under 
Fig. 1. Mean $( \pm \mathrm{SE})$ relative growth rate $(\mathrm{RGR})$ in length for the four experimental groups: $\mathrm{H}$, handled; $\mathrm{NH}$, nonhandled; $\mathrm{D} 3$, a stocking density of three fish; D6, a stocking density of six fish; $\mathrm{BL}$, total body length; ${ }^{*}, p<0.05$ (group NH-D6 versus group H-D6 by Student's $t$ test).

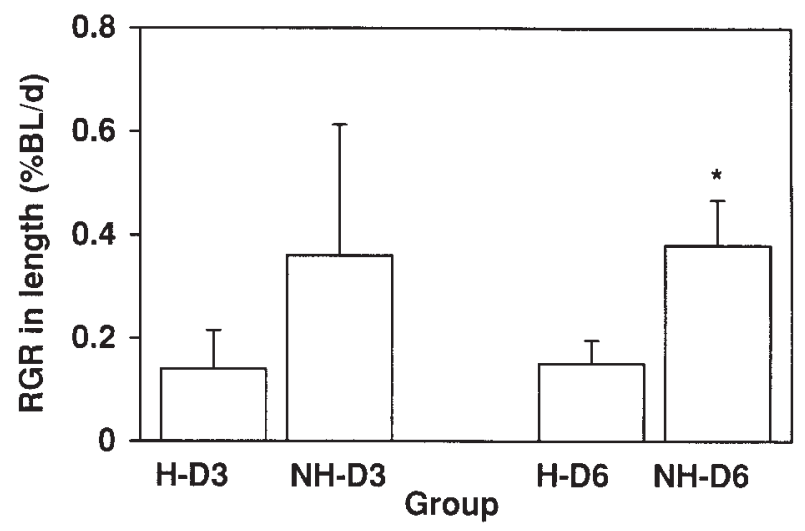

constant water temperature $\left(12^{\circ} \mathrm{C} \pm 0.5\right)$ and photoperiod $(12 \mathrm{~h}$ light : $12 \mathrm{~h}$ dark). They were fed to satiation once daily.

Eighteen fish were randomly allocated to each of four groups, according to a $2 \times 2$ factorial repeated measures design. Fish were individually marked using $0.02 \mathrm{~mm}$ diameter platinum wires inserted at different positions in the fins or tail. After an acclimation period of 2 weeks, the experiment was started on 3 November 1994 and lasted $41 \mathrm{~d}$. Two treatments with two levels each were applied: (1) 'handling $(\mathrm{H})$ for weighing and length measurement every $2 \mathrm{~d}$ versus no handling $(\mathrm{NH})$ and filming with a stereo-video technique and (2) stocking densities of three (D3) versus six (D6) fish per $150 \mathrm{~L}$. Densities higher than six were avoided, because of increased difficulties in identifying individual fish with the video cameras.

\section{Measurement techniques}

Fish in the handled groups were individually weighed $( \pm 0.01 \mathrm{~g}$ wet) and measured $( \pm 0.05 \mathrm{~cm}$ total length) every $2 \mathrm{~d}$, after being lightly anaesthetized by immersion in a $1 \mathrm{mg} / \mathrm{L}$ solution of MS222 (tricaine methane sulfonate) for about $30 \mathrm{~s}$. The nonhandled groups were filmed with stereo-video cameras (setup as developed by Ménard (1991)) at 2-d intervals for 10 min each time, to obtain records of fish length in three-dimensional space. We adapted, for our purpose, the program developed to estimate the swimming speed of fish from coordinates $x, y$, and $z$ of the head and the tail (Boisclair 1992). Each fish was digitized in positions perpendicular to the axes of the camera. Coordinates of the head and tail in each position were used to estimate fish length. The average of the three lengths was retained for further analysis.

The accuracy of the stereo-video technique in relation to the variability of the growth rate in length over time was assessed by measuring six marked fish $(13.05 \pm 0.64 \mathrm{~cm}$ (mean $\pm \mathrm{SE})$ total body length) with a ruler. The same fish were filmed with stereovideo cameras. Direct length measurements and length estimates derived from image analysis were compared. They did not differ significantly on the basis of relative errors (paired $t$ test, $p>0.05$ ); the difference between actual and estimated fish length (mean + $\mathrm{SE})$ was $0.050+0.313 \mathrm{~cm}$, which represents an error of $0.38 \%$ relative to the mean total body length of the six fish. These accuracy estimates are comparable with those reported in Ménard (1991).

We calculated fish length by image analysis at 4-d intervals. The sensitivity analysis of the video images would not allow the detection of differences in length at 2-d intervals (Aboul Hosn 1997). The resulting time series of growth rates in length obtained by im- age analysis were composed of 20 observations (10 observations on nine nonhandled fish and 10 observations on nine handled fish).

\section{Computations}

The relative growth rate (RGR) in length was expressed as the mean rate of change in length (\% body length $(\mathrm{BL}) / \mathrm{d})$. It was calculated using the following equation from Ricker (1979):

[1] RGR in length $=\frac{L-1}{T-t} \times \frac{100}{l}$

where $l$ and $L$ represent, respectively, the initial and final length (cm) during the time interval of length $T-t$ of $4 \mathrm{~d}$. The RGR in mass was calculated in a similar way for the handled groups. Standardized RGRs (SRGRs) were obtained by centring each individual series of RGRs around the mean of the series and dividing the result by the standard deviation of the series.

\section{Statistical analyses}

\section{Repeated-measures ANOVA}

Handling, stocking-density, and time effects on growth rates, and their interactions, were assessed by repeated-measures ANOVA. Normality was assessed at $\alpha=0.05$. The ANOVA model used for the analysis of the time series of SRGR in length was

$$
\begin{aligned}
& Y_{i j t k}=m+a_{i}+b_{j}+c_{t}+\operatorname{Ind}_{k \mid(i, j)}+(a b)_{i j}+(a c)_{i t} \\
& +(b c)_{j t}+(a b c)_{i j t}+e_{i j t k} \\
& (i=1,2 ; j=1,2 ; t=1, \ldots, 10 ; k=6 \\
& \text { if } j=1 \text { and } 3 \text { if } j=2 \text { ) }
\end{aligned}
$$

where $Y_{i j t k}$ is the SRGR in length at time $t$ for fish $k$ from treatment combination $i, j ; m$ is the overall mean of the growth rate; $a_{i}$ is the main effect of handling $i ; b_{j}$ is the main effect of stocking density $j$; $c_{t}$ is the main effect of time $t ; \operatorname{Ind}_{k \mid(i, j)}$ is the effect of fish $k$ from treatment combination $i, j ;(a b)_{i j}$ is the handling $\times$ stocking density interaction; $(b c)_{j t}$ is the handling $\times$ time interaction; $(a c)_{i t}$ is the stocking density $\times$ time interaction; $(a b c)_{i j t}$ is the three-factor interaction; and $e_{i j t k}$ is the random experimental error. Time was crossed with each treatment factor and all three factors were considered fixed; replicates were provided by the individual fish nested within each treatment combination.

\section{Frequency-domain analysis}

Multifrequential-periodogram analysis (Dutilleul 1990) was used to detect periodicities in the group-mean series of the SRGRs in length and mass. Periodicities corresponding to significant frequencies were calculated by multiplying the number of observations ( $n=10$ observations) by the sampling interval $(\triangle t=4 \mathrm{~d}$ ) and then dividing the product by the frequency considered.

The analysis of variance of the finite Fourier transform of replicated time series (Brillinger 1973; Dutilleul 1990) was used to assess the differences in the frequency domain among the levels of each treatment factor (main effects) and their combinations (interactions). This method allows testing of whether the rhythm characteristics in amplitude and phase at the Fourier frequencies of the SRGR time series are different among the levels of the factors considered (Schelstraete et al. 1992; Dutilleul 1997).

\section{Results}

\section{Treatment and time effects on growth rates}

Across the four groups, the mean $( \pm \mathrm{SE}) \mathrm{RGR}$ in length was $0.26 \pm 0.07 \% \mathrm{BL} / \mathrm{d}(n=180)$. For the two handled groups, the mean $( \pm \mathrm{SE}) \mathrm{RGR}$ in mass was $0.51 \pm 0.32 \%$ 
Fig. 2. Temporal trajectories for the standardized relative growth rates (SRGRs) in length \pm SE per level of each factor for handled versus nonhandled fish $(a)$ and stocking densities of three versus six fish $(b)$.
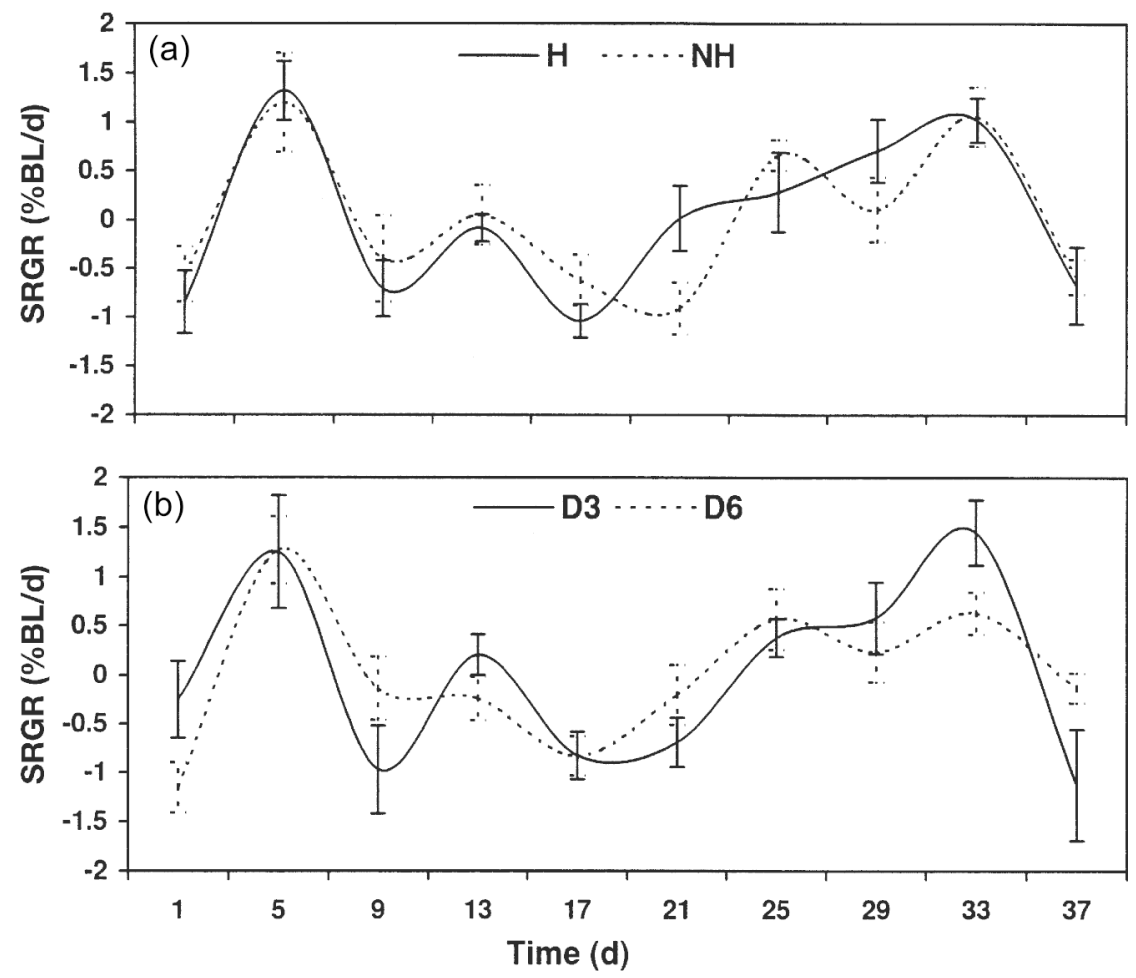

Table 1. Repeated-measures ANOVA for between-fish effects, tested on the relative growth rate in length, and within-fish effects, tested on the standardized growth rate in length.

\begin{tabular}{|c|c|c|c|c|c|c|}
\hline \multirow[b]{2}{*}{ Source of variation } & \multirow[b]{2}{*}{ df } & \multirow{2}{*}{$\begin{array}{l}\text { Mean } \\
\text { square }\end{array}$} & \multirow[b]{2}{*}{$F$} & \multirow[b]{2}{*}{$p>F$} & \multicolumn{2}{|c|}{ Adjusted $p>F$} \\
\hline & & & & & $\mathrm{G}-\mathrm{G}$ & $\mathrm{H}-\mathrm{F}$ \\
\hline \multicolumn{7}{|l|}{ Between fish } \\
\hline Handling & 1 & 2.09 & 4.14 & 0.06 & & \\
\hline Stocking density & 1 & 0.01 & 0.02 & 0.89 & & \\
\hline Handling $\times$ stocking density & 1 & $<0.01$ & 0.01 & 0.99 & & \\
\hline Error & 14 & 0.51 & & & & \\
\hline \multicolumn{7}{|l|}{ Within fish } \\
\hline Time & 9 & 0.9980 & 1.99 & 0.0459 & 0.0457 & 0.0459 \\
\hline Time $\times$ handling & 9 & 0.1761 & 0.18 & 0.9962 & 0.9841 & 0.9962 \\
\hline Time $\times$ stocking density & 9 & 0.3964 & 0.39 & 0.9359 & 0.8844 & 0.9359 \\
\hline Time $\times$ handling $\times$ stocking density & 9 & 1.1010 & 1.01 & 0.4363 & 0.4257 & 0.4363 \\
\hline Error (time) & 126 & 1.0050 & & & & \\
\hline
\end{tabular}

body mass/d $(n=90)$. The overall mean level of RGR in length throughout the experiment for nonhandled fish was about twofold higher than that for handled fish (Fig. 1). Although substantial in magnitude, this difference was not statistically significant at the 0.05 level $(p=0.06)$, as shown in the repeated measures analysis results (Table 1). However, since the $p$ value was close to significance, and the full model (eq. 2) included a highly nonsignificant handling $\times$ stocking density interaction (Table 1), we ran a Student's $t$ test, which showed that fish stocked at density six grew significantly faster when not handled than when handled (Fig. 1).

Stocking-density effects were not significant. The time factor, on the other hand, significantly affected growth rates
(Table 1; Fig. 2), but the interactions between treatment and time were not significant.

\section{Periodicities in growth rates}

Growth trajectories suggested the existence of a rhythm of about a 8-d periodicity in the RGR in length (Fig. 2; Table 2). The multifrequential-periodogram analysis showed that, on average, a predominant periodicity of about $8 \mathrm{~d}$ (4.72 cycles) was shared by the four groups in their SRGR in length. A second periodicity of $17 \mathrm{~d}$ (2.32 cycles) was also shared by the four groups but was found to be significant only for groups H-D3 and NH-D3 (Table 2). 
Table 2. Periods estimated by the stepwise procedure of the multifrequential-periodogram analysis performed for the group-mean series of SRGR in length and, in parentheses, for the groupmean series of SRGR in mass (available only for handled groups).

\begin{tabular}{lccrr}
\hline & Group & & \\
\cline { 2 - 4 } Step & H-D3 & H-D6 & NH-D3 & NH-D6 \\
\hline 1 & $8.87^{* *}\left(11.17^{* *}\right)$ & $8.57 * *\left(11.23^{* *}\right)$ & $8.46^{* *}$ & $8.02 * *$ \\
$2^{a}$ & $34.48(23.53)$ & $37.38(38.46)$ & 34.48 & 38.46 \\
$3^{a}$ & $16.00\left(4.93^{* *}\right)$ & $16.95(6.47 * *)$ & 17.39 & 18.75 \\
Value of periodogram $^{b}$ & 7.19 & 8.89 & 8.95 & 8.76 \\
\hline
\end{tabular}

${ }^{a}$ Periods estimated at this step are likely to correspond to temporal autocorrelation rather than discrete rhythmic components.

${ }^{b}$ The value of the periodogram is reported at step 3 . The total variance of each group-mean series is equal to 9.00 by standardization.

$* * P<0.01$. The amplitude of the rhythmic component is highly significant.

Table 3. Analysis of variance of the finite Fourier transform of replicated time series ( 1 fish $=1$ replicate) of SRGR in length at Fourier frequencies $\omega_{k}=1, \ldots, 5$ (number of cycles over $40 \mathrm{~d}$ ); $F\left(\omega_{k}\right)$ indicates the Fisher-Snedecor $F$ statistic equivalent to Wilk's $\lambda$.

\begin{tabular}{|c|c|c|c|c|c|c|}
\hline \multirow{2}{*}{$\begin{array}{l}\text { Fourier } \\
\text { frequency } \\
\left(\omega_{k}\right) \\
\end{array}$} & \multicolumn{2}{|c|}{ Handling } & \multicolumn{2}{|c|}{ Stocking density } & \multicolumn{2}{|c|}{$\begin{array}{l}\text { Handling } \times \text { stocking } \\
\text { density }\end{array}$} \\
\hline & $F\left(\omega_{k}\right)$ & $p>F\left(\omega_{k}\right)$ & $F\left(\omega_{k}\right)$ & $p>F\left(\omega_{k}\right)$ & $F\left(\omega_{k}\right)$ & $p>F\left(\omega_{k}\right)$ \\
\hline 1 & 0.07 & 0.93 & 0.02 & 0.98 & 1.71 & 0.22 \\
\hline 2 & 0.09 & 0.92 & 0.06 & 0.94 & 0.03 & 0.97 \\
\hline 3 & 0.06 & 0.94 & 0.78 & 0.48 & 1.25 & 0.32 \\
\hline 4 & $<0.01$ & 0.99 & 0.56 & 0.59 & 0.25 & 0.78 \\
\hline 5 & 0.57 & 0.46 & 0.28 & 0.61 & 2.41 & 0.14 \\
\hline
\end{tabular}

The analysis of the SRGR in mass showed a common periodicity of about $11 \mathrm{~d}$ in both handled groups, a second 6-d periodicity in group H-D6, and a 5-d periodicity in group H-D3 (Table 2).

\section{Treatment effects on growth rate rhythm characteristics}

Handled and nonhandled fish (Fig. 2a) and fish stocked at density three versus density six (Fig. $2 b$ ) seemed to follow similar patterns of growth in length. Although group H-D6 showed a slight shift in phase compared with the other groups, fish growth rates were synchronized, reaching their highest peaks and lowest troughs almost at the same time (Fig. 2). Standardization of the RGR contributed to reducing interindividual differences. This was demonstrated by the ANOVA of the finite Fourier transform, which showed that the rhythmic characteristics of the growth rate in length were not significantly modified by handling or stocking density (Table 3).

\section{Discussion}

The results of the present study show that handling reduces the sample mean growth rate in length overall, although when considered on a time by time basis, the effects of handling, stocking density, and the combination of these factors on growth were not significant. This was probably due to interindividual variability among fish. Although fish of the same size were chosen at the beginning of the experiment, the differences among fish became greater as the experiment proceeded, owing to social hierarchies developed in the aquaria. For instance, fish 3 in the group NH-D3 had a mean RGR of $0.87 \pm 0.303 \% \mathrm{BL} / \mathrm{d}$, which was 8 times higher than the slowest growing fish in that group.

Our results also showed that the growth rate of brook trout fluctuated significantly over time. Analysis of these fluctuations revealed rhythmic patterns characterized by periodicities of 5 and $11 \mathrm{~d}$ in the SRGR in mass and 8 and $17 \mathrm{~d}$ in the SRGR in length. Besides the conventional seasonal, lunar, semilunar, and circadian rhythms, the present results confirmed the infradian growth rhythms in brook trout demonstrated in Aboul Hosn et al. (1997). In Aboul Hosn et al. (1997), the periodicities were very similar to the results of the present study for growth rate in mass ( 5 and $10 \mathrm{~d}$ ) but were longer for growth rate in length (4 and $6 \mathrm{~d}$ ). We do not suspect that handling or stocking density are the cause of such longer periodicities, since the same 8-d periodicity was found in all groups regardless of the treatment applied. We believe the short periodicity of $4 \mathrm{~d}$ was simply not detected in this experiment, not because it is absent from the growth spectrum, but because the interval separating successive data points used for the analysis was $4 \mathrm{~d}$. Consequently the shortest detectable period was $8 \mathrm{~d}$.

Our main interest in this study was to test whether handling or stocking density altered the characteristics of the rhythms (amplitude, phase, and periodicity). Our results showed that there was no evidence of handling effects, in combination with stocking density or not, on the rhythm characteristics of growth. This finding was essential for the pursuit of our study on rhythms in growth and feeding of brook trout 
under different treatments (W. Aboul Hosn, P. Dutilleul, and D. Boisclair, in preparation ${ }^{2}$.

In the present experiment, mild anaesthetic concentration and low stocking-density levels might not have been strong enough to trigger changes in growth rhythms. In fact, the use of anaesthetics in general has been shown to reduce stress in fish (Strange and Schreck 1978), and this specific anesthetic, MS222, has been shown to clear rapidly from the blood of brook trout upon their transfer to fresh water (Houston and Woods 1972). In addition, we used a very dilute solution of MS222 (1 vs. $100 \mathrm{~mL} / \mathrm{L}$ ) and a shorter exposure time (a few seconds vs. 2 and 15 min) (Hunn 1970). Blood sample analyses performed before and after exposure, showed no change in the cortisol concentrations (M. Tang, unpublished observations). Reduced impacts of handling might also have resulted from behavioral adaptations, such as fish becoming accustomed to repetitive handling or being fed to satiation and, therefore, being less sensitive to handling stress (Vijayan and Moon 1992).

Growth rhythms, on the other hand, might be totally intrinsic and, therefore, their properties would not be changed by external factors, such as handling, stocking density, or other factors. Similar rhythms were found in three different experiments; for instance, in this experiment, fish were fed to satiation in the month of November, compared with a 2.5\% ration in August-September (Aboul Hosn et al. 1997) or a $1.2 \%$ ration in February-March (W. Aboul Hosn, P. Dutilleul, and D. Boisclair, in preparation ${ }^{2}$ ). The constancy in the characteristics of the rhythms suggests that rhythms are probably inherited and unmodified by environmental factors.

The existence of intrinsic rhythms in growth has many implications for physiological studies in fish. In assessing treatment effects on growth or other related physiological variables, researchers should take into account the variability of fish growth, owing to intrinsic infradian rhythms. For instance, a significant decrease in growth could be wrongly attributed to a treatment, when in fact a fish is in the trough of its growth cycle and vice versa. In addition, since the main objective of our present study was to evaluate the effects of handling and stocking density on the growth rhythms of brook trout, we did not present models that describe growth rhythms. The models we presented in Aboul Hosn et al. (1997), and that include the short-term periodicities, predicted the growth rate of fish on a short-term basis very well. Therefore, we believe that infradian rhythms in fish need to be researched further, just like seasonal, circadian, and lunar rhythms.

\section{Acknowledgements}

This work was supported by scholarships from the Natural Sciences and Engineering Research Council of Canada (NSERC), le Fonds pour la formation de chercheurs et l'aide à la recherche (FCAR), and Groupe de recherche interuniversitaire en limnologie et écologie aquatique to W.A.H. The work of P.D. and D.B. was supported by NSERC and FCAR. We benefited from the use of computing facilities at
McGill University. We thank F. Marchand and M. Tang for technical support.

\section{References}

Aboul Hosn, W. 1997. Analysis of growth rythms and activity patterns of brook trout Salvelinus fontinalus, based on replicated time series and time-dependent transition probabilities. Ph.D. thesis, McGill University, Montreal, Quebec, Canada.

Aboul Hosn, W., Dutilleul, P., and Boisclair, D. 1997. Use of spectral analysis to estimate short-term periodicities in growth rates of brook trout (Salvelinus fontinalis). Can. J. Fish. Aquat. Sci. 54: $1532-1541$.

Barton, B.A., and Iwama, G.K. 1991. Physiological changes in fish from stress in aquaculture with emphasis on the response and effects of corticosteroids. Annu. Rev. Fish Dis. 1: 3-26.

Boisclair, D. 1992. An evaluation of the stereocinematographic method to estimate fish swimming speed. Can. J. Fish. Aquat. Sci. 49: 523-531.

Brillinger, D.R. 1973. The analysis of time series collected in an experimental design. In Multivariate analysis III. Edited by P.R. Krishnaiah. Academic Press, London. pp. 241-256.

Brown, J.A., Hohansen, P.H., Colgan, P.W., and Mathers, R.A. 1987. Impairment of early feeding behavior of large mouth bass by pentachlorophenol exposure: a preliminary assessment. Trans. Am. Fish. Soc. 116: 71-78.

Brown, M.E. 1946. The growth of brown trout (Salmo trutta Linn.). II. The growth of two-year trout at a constant temperature of $11.5^{\circ}$ C. J. Exp. Biol. 22: 130-144.

Campana, S.E. 1984. Lunar cycles of otolith growth in the juvenile starry flounder (Platichthys stellatus). Mar. Biol. (Berlin), 80: 239-246.

Campana, S.E., and Neilson, J.D. 1982. Daily growth increments in otoliths of starry flounder, Platichthys stellatus, and the influence of some environmental variables in their production. Can. J. Fish. Aquat. Sci. 39: 937-942.

Dutilleul, P. 1990. Apport en analyse spectrale d'un périodogramme modifié et modélisation des séries chronologiques avec répétitions en vue de leur comparaison en fréquence. D.Sc. dissertation, Université catholique de Louvain, Louvain-La-Neuve, Belgium.

Dutilleul, P. 1997. Incorporating scale in ecological experiments: data analysis. In Ecological scale: theory and applications. Edited by D.L Peterson and V.T. Parker. Columbia University Press, New York. pp. 387-425.

Eddy, F.B. 1981. Effects of stress on osmotic and ionic regulation in fish. In Stress and fish. Edited by A.D. Pickering. Academic Press, London. pp. 77-102.

Farbridge, K.J., and Leatherland, J.F. 1987. Lunar cycles of coho salmon (Onchorhyncus Kisutch). I. Growth and feeding. J. Exp. Biol. 129: 165-178.

Fonds, M. 1979. A seasonal fluctuation in growth rate of young plaice (Pleuronectes platessa) and sole (Solea solea) in the laboratory at constant temperatures and a natural daylight cycle. In Cyclic phenomena in marine plants and animals. Edited by R.J. Hartnoll. Pergamon Press, London. pp. 151-156.

Houston, A.H., and Woods, R.J. 1972. Blood concentrations of tricaine methanesulfonate in brook trout (Salvelinus fontinalis) during anaesthetisation, branchial irrigation and recovery. J. Fish. Res. Board Can. 29: 1344-1346.

\footnotetext{
${ }^{2}$ W. Aboul Hosn, P. Dutilleul, and D. Boisclair. Effects of stocking density and ration level on periodicities in the growth rates and daily food intake of brook trout, Salvelinus fontinalis. In preparation.
} 
Hunn, J.B. 1970. Dynamics of MS-222 in the blood and brain of freshwater fishes during anesthesia. U.S. Bur. Sport Fish. Wildl. Resour. Publ. 42: 1-8.

Leatherland, J.F., and Sonstegard, R.A. 1984. Pathobiological responses of feral teleosts to environmental stressors: interlake studies of the physiology of Great Lakes salmon. In Contaminant effects on fisheries. Edited by V.W. Cairns, P.V. Hodson, and J.O. Nriagu. Wiley, New York. pp. 115-149.

Mazeaud, M.M., and Mazeaud, F. 1981. Andrenergic responses to stress in fish. In Stress and fish. Edited by A.D. Pickering. Academic Press, New York. pp. 49-75.

Ménard, C. 1991. Utilisation de la vidéo pour mesurer les poissons in situ. M.Sc. thesis, Université de Montréal, Montréal.

Pannella, G. 1971. Fish otoliths: daily growth layers and periodical patterns. Science (Washington, D.C.), 173: 1124-1127.

Pickering, A.D. 1990. Stress and the supression of somatic growth in teleost fish. In Progress in comparative endocrinology. Edited by A. Epple, C.G. Scanes, and M.H. Stetson. Wiley, New York. pp. 473-479.

Planes, S. 1993. Analyse de la croissance des larves et juvéniles de loups (Dicentrarchus Labrax). C. R. Acad. Sci. serie 3, Océanographie biologique, 316: 197-203.

Ricker, W.E. 1979. Growth rates and models. In Fish physiology. Vol. 8. Edited by W.S. Hoar, D.J. Randall, and J.R. Brett. Academic Press, New York. pp. 677-743.
Schelstraete, I., Knaepen, E., Dutilleul, P., and Weyers, M.J. 1992. Maternal behavior in the Wistar rat under atypical Zeitgeber. Physiol. Behav. 52: 189-193.

Schreck, C.B. 1981. Stress and compensation in teleost fishes: response to social and physical factors. In Stress and fish. Edited by A.D. Pickering. Academic Press, New York. pp. 295-321.

Strange, R.J., and Schreck, C.B. 1978. Anesthetic and handling stress on survival and cortisol concentration in yearling chinook salmon (Onchorhynchus tshawytscha). J. Fish. Res. Board Can. 35: $345-349$.

Vijayan, M.M., and Moon, T.W. 1992. Acute handling stress alters hepatic glycogen metabolism in food-deprived rainbow trout (Onchorhynchus mykiss). Can. J. Fish. Aquat. Sci. 49: 2260-2266.

Vijayan, M.M., Ballantyne, J.S., and Leatherland, J.F. 1990. High stocking density alters the energy metabolism of brook charr (Salvelinus fontinalis). Aquaculture, 88: 371-381.

Wagner, G.F., and McKeown, B.A. 1985. Cyclical growth in juvenile rainbow trout (Salmo gairdneri). Can. J. Zool. 63: 24732474.

Wang, S.B., and Houde, E.D. 1994. Energy storage and dynamics in bay anchovy (Anchoa mitchilli). Mar. Biol. (Berlin), 121: 219-227. 